\title{
Determination of the Optimal Buoy Shape for A Concept Wave Energy Converter to Harness Low Amplitude Sea Waves using Numerical Simulation
}

\author{
Olakunle Kayode $^{1}$, Olufemi Adebola Koya ${ }^{2}$, Titus Oluwasiji Ajewole ${ }^{3}$ \\ (Received: 30 August 2019 / Revised: 15 September 2019 / Accepted: 29 September 2019)
}

\begin{abstract}
Wave Energy Converter (WEC) for harnessing low amplitude sea waves characteristic of the Gulf of Guinea coast. It has been established that shape of buoy is one of the main parameter affecting the efficiency of a point absorber WEC. Based on best buoy shapes as reported in literature, two shapes are selected for comparison: cone-cylinder composite buoy and Concave wedge shaped buoy. The WEC's buoy and the power take off were mathematically modelled as a mass-spring-damper system. The buoys hydrodynamic coefficients were computed using strip theory, while the simulation in the time domain was executed using MATLAB. Impute parameters referred to as the sea states, in five levels, were described by the significant wave height $H_{s}$ and the corresponding energy period $T_{e}$, typical of the gulf. Output parameters are displacement, velocity, acceleration and force of the buoys, as well as the instantaneous power output of the WEC. For the levels considered, the optimum sea state for the two buoys peaked at level $4\left(H_{s}=1.5 \mathrm{~m}, T_{e}=14 \mathrm{~s}\right)$, with concave wedge buoy having an optimal power output of $8 \mathrm{~kW}$ while that of cone-cylinder being $3.7 \mathrm{~kW}$. For the other levels the wedge buoy also consistently gives relatively greater power output than the cone cylinder buoy.
\end{abstract}

Keywords—buoy shape, low amplitude waves, wave amplifying device, wave energy converter.

\section{INTRODUCTION}

$\mathrm{T}$ he rising cost of fossil fuels as well as negative impact of such energy sources on global climate is raising opposition to their utilization. As a consequence, in recent years, the demand for renewable energy is increasing and gaining wider acceptance. When compared with various sources of renewable energy such as wind and solar, sea wave energy has higher energy density, is fairly predictable, more reliable and fairly constant on seasonal basis [1]. Globally, the best wave climates, whose annual average power levels are between 20 and $70 \mathrm{~kW} / \mathrm{m}$ or higher, are found in zones from $30^{\circ}$ to $60^{\circ}$ latitude [2]. However, attractive wave climates are found also within $\pm 30^{\circ}$ latitude, where the lower power level (as a result of relatively lower amplitude waves) is compensated by smaller power variability [3]. Nigeria coastal belt is located within the later zone, precisely on the Gulf of Guinea between latitudes $04^{\circ} 30^{\prime}$ and $06^{\circ} 30^{\prime} \mathrm{N}$ of the equator. There are many isolated Nigeria coastal communities not connected to the national grid. Diesel generators are a major source of electricity in these isolated coastal communities. Since the power production per unit price of a diesel generator is higher than that of national grid, renewable energy sources in these communities are cost competitive. That most of these communities rely on diesel power generators had been

Olakunle Kayode, Department of Mechanical Engineering, Osun State University, PMB 4494, Osogbo, Nigeria. E-mail :-

Olufemi Adebola Koya, Department of Mechanical Engineering, Obafemi Awolowo University, Ile-Ife, Nigeria. E-mail :-

Titus Oluwasiji Ajewole, Department of Electrical and Electronic Engineering, Osun State University, Osogbo, Nigeria. E-mail :- highlighted by [4][5], thus harnessing the low amplitude wave energy of the region may be a solution to their energy needs. However United Nations Environment Programme report [6] states that studies have shown that West African sub-region has the potential annual wave energy of $300 \mathrm{MWh} / \mathrm{m}$ of wave crest which is far below the highest reading of 535 for the north Atlantic ocean (latitude $30^{\circ}$ to $60^{\circ}$ ). Based on this, the report concluded that the future of wave energy in West African is not encouraging, unless a process is developed that can economically utilize relatively the region's small and irregular wave formations.

In recent years, several kinds of ocean power converter prototypes have been developed, according to the expertise of each inventing team and/or specific issues from the local sea where it was planned for. In fact, Wave Energy Converter (WEC) design is still in its infancy with significant research being devoted to quest for more efficient and reliable designs. So far, no typology has provided a clear advantage over others in term of efficiency, cost of production, and maintenance requirements, thus new devices continues to be conceived [7]. There are more than 20 wave energy projects around the world. Nearly all of which are still at pilot stage either as a proof of concept or as part of a research facility. Some are connected to the local grid but none are contributing significantly to a national grid [8][9]. 
A point absorbing WEC with a direct drive Power Take Off (PTO) system is most efficient and beneficial in converting the low speed oscillating motion of ocean waves [10]. Previous works on point absorber WEC conceived to operate in similar wave climates tends to utilize the wave as presented by nature without effort to artificially increase the incident wave energy density in order to boost their efficiency. Researches at improving efficiency of point absorber had focused on the premise that if WEC is tuned to resonate, the wave energy can be extracted efficiently due to the amplified motions of the buoy. However, most existing WECs models use the resonance only at single resonant frequency, so it is hard to extract energy outside the narrow resonant frequency region [11][12]. An alternative proposed here is to first increase the energy content of incident wave on the primary interface (the buoy) couple with the use of an efficient buoy shape for maximum energy extraction thus reducing design complications that may arise in effort to tune the WEC to resonate to a single resonant frequency. This work present a concept (WEC) to efficiently harness as much as possible the energy content of low amplitude waves characteristic of the Gulf of Guinea by providing a means of amplifying the waves thus increasing its energy density and focusing the waves thus amplified unto the primary interface (a buoy) of a point absorber energy converter. The focus, therefore, of this work is to determine the optimum shape of buoy for a point absorber in the concept WEC thus proposed. The empirical research of the wave amplification aspect of the concept WEC is the subject of a separate paper.

\section{METHOD}

Device of choice considered to be appropriate for harnessing the low amplitude waves, as predominant in Nigeria offshore, is based on point absorber, which is able to operate in a wave climate characterized by low amplitude waves.

\section{A. Description of the Concept Device}

The device conceived in this research is to consist of three main parts. The first part is a Wave Amplifying Device (WAD), meant to focus the incident wave into a narrow parallel wall channel (henceforth referred to as the Throat) in order to create a quasi- two dimensional wave with attendant magnification of the wave height, and thus the power content per unit length of wave crest in the throat. There is also a second part, which consists of a buoy (or several buoys in-line) floating in the throat section, with the buoy(s) to be connected to the Power Take Off (PTO) located on a platform mounted on a platform above the throat section. To constitute the third part of the device is the PTO.

The WAD is conceived as utilising an adjacent portion of existing port breakwater in addition to its own floating breakwater or wave reflectors to be inclined at an angle to the existing one with the wider end opening to the incident waves and the narrower end opening into the throat section. Integration of WECs to existing marine structures in order to minimise overall cost of construction is gaining traction [13] - [18]. The concept WEC configuration and how it may be integrated to a port breakwater is as depicted in Figure 1. Reference [19] shows that the wave power density, $\mathrm{P}\left(\mathrm{Wm}^{-1}\right)$, available in each meter of crest length is:

$\mathrm{P}=500 \mathrm{H}_{\mathrm{S}}^{2} \mathrm{~T}_{\mathrm{e}}$

Where $\mathrm{H}_{\mathrm{S}}$ is the significant wave height and $\mathrm{T}_{\mathrm{e}}$ is the mean wave period. The implication of Eq. 1 is that when wave height is double, it generates four times as much power. Determination of the optimum reflectors inclination angle for the WAD as well as determination of the optimum buoy shape to be mounted in the throat are both crucial to the overall efficiency of the device, however the determination of the optimum buoy shape is the subject of this research.

\section{B. Optimization of the primary interface}

One of the main parameters affecting the efficiency of a point absorber WEC is the shape of buoys [20][22].Optimization of geometry and inertia of the shape provides a good way of increasing the captured energy of an oscillating body [23]. Based on best buoy shapes as reported in literature [20]-[22], two buoy shapes are, in this research, selected for comparison. The two are the cone-cylinder composite buoy and the concave wedge shaped buoy. Projected real life dimensions of the two are shown in Figure 2. Both designs have similar horizontal extent (as constrained by the throat), draft, and weight, leaving the shape as the only physical difference. The material of fabrication is to be polyurethane.
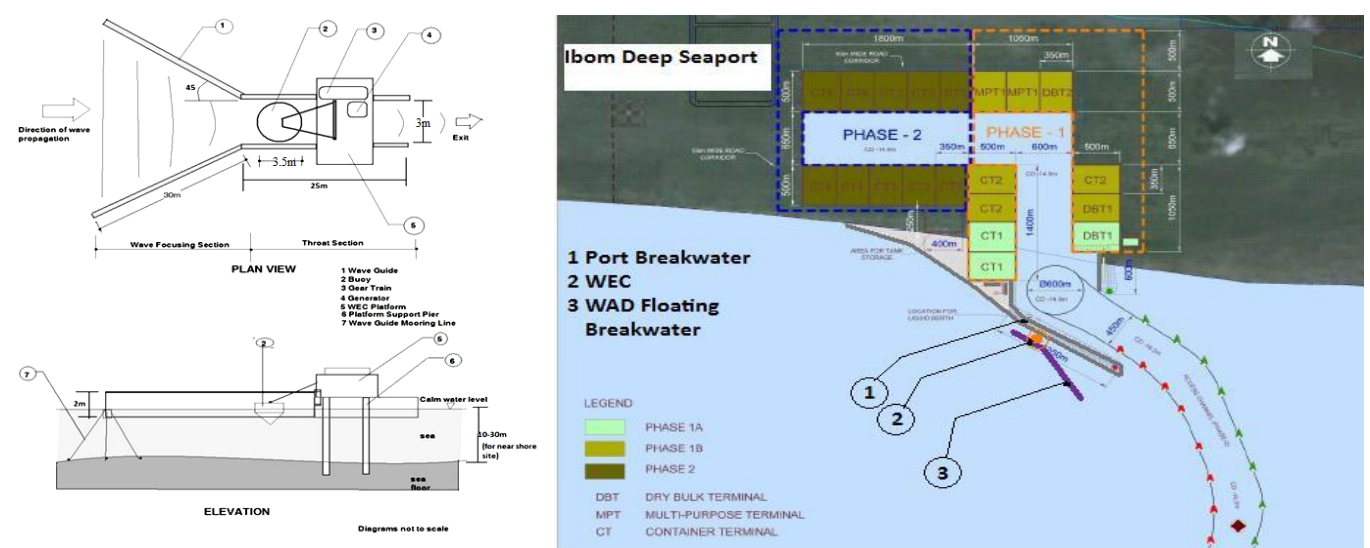

Figure. 1. (a) A schematic of the concept wave energy converter with essential dimensions. (b) WEC as it may be integrated to a port breakwater (back ground image: Ibom deep sea port, Nigeria. http://ndlink.org) 


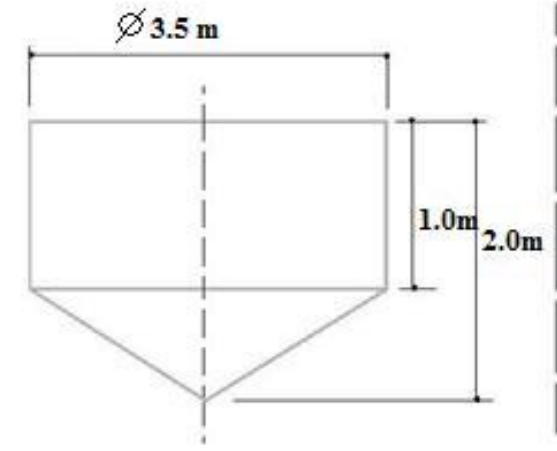

Cone Cylinder Buoy

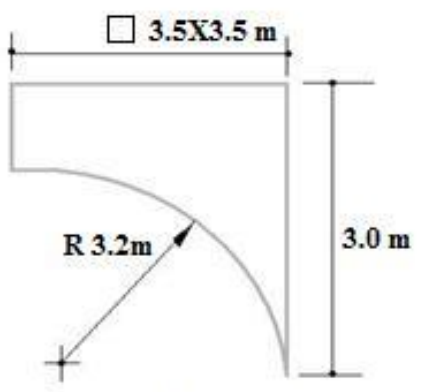

Concave Wedge Buoy

Figure. 2. Geometry of the concept WEC buoys

\section{Mathematical Modelling of the Concept Device}

The WEC's buoy and PTO in the throat section is modelled on the principle of damped forced mechanical vibration, being presented as a mass-spring-damper system as shown in Fig. 3. This approach of modelling point absorber WEC is similar to those employed in [24-
29].Generally there are six degrees of freedom (Fig. 3, inset) for a floating body, but for the purpose of this study, the primary interface (buoy) is constrained to move only in heave.
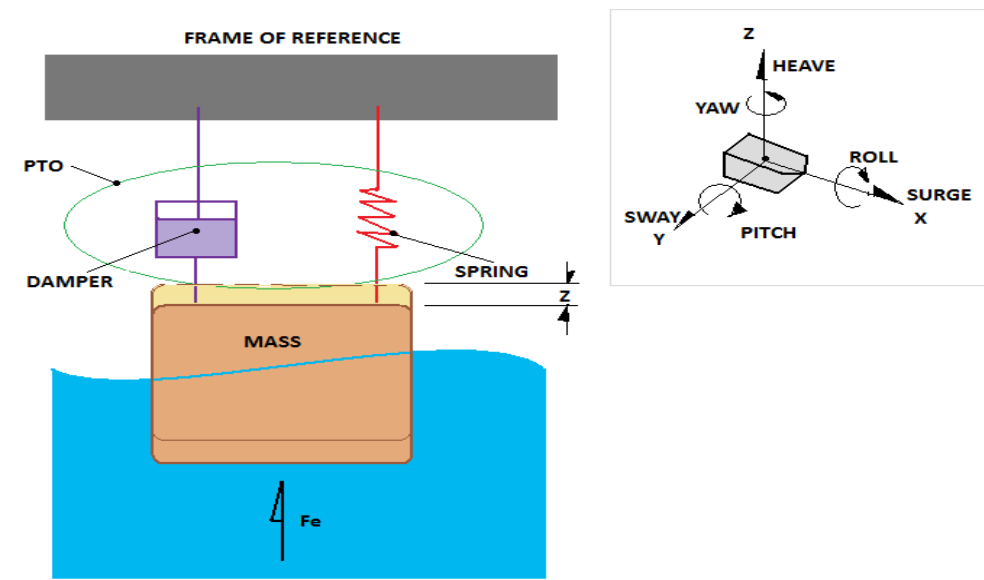

Figure. 3. The WEC represented as a mass-spring-damper system.

The PTO model consists of a damper and spring system and the damper was idealized as having viscous (linear) damping. Excitation force of the sea waves was assumed, for simplicity purpose, to be monochromatic. Thus, the equation describing its motion, based on Newton's second law of motion, is given by,

$$
M \ddot{Z}=f_{h}(t) f_{p}(t)
$$

Where; $M$ is the mass $(\mathrm{kg})$ of the buoy; $\ddot{Z}$ is the buoy's acceleration in heave; $f_{h}$ is the hydrodynamic force acting on the buoy wetted surface; and $f_{p}$ is the force exerted by the PTO mechanism. The heave $f_{h}$ is the sum of three forces, thus:

$$
f_{h}=f_{e}+f_{r^{-}} f_{h s}
$$

Where $f_{e}$ is the excitation force from incident wave; $f_{r}$ is the radiation force due to the buoys motion in water; and $f_{h s}$ is the hydrostatic force. The hydrostatic force is expressed as:

$f_{h s}=-\rho g S z$

Where $\rho$ is the density of the sea water (in $\mathrm{kg} / \mathrm{m}^{3}$ ); $\mathrm{g}$ is the acceleration due to gravity $\left(\mathrm{m} / \mathrm{s}^{2}\right) ; \mathrm{S}$ is the cross sectional area of the buoy at the water plane; and $Z$ is buoy's displacement in heave $(\mathrm{m})$.

Thus, equation 2 is expressed as:

$M \ddot{Z}=f_{e}+f_{r^{-}} \rho \mathrm{gSz}+f_{p}$

With $f_{r}$ decomposed to:

$f_{r}=-A \ddot{Z}-B \dot{Z}$

Where $A$ and $B$ are added mass ( $\mathrm{kg}$ ) and radiation damping ( $\mathrm{kg} / \mathrm{s})$, respectively; and $\dot{Z}$ is buoy's velocity in heave $(\mathrm{m} / \mathrm{s})$. The coefficients were computed using the Strip Theory method [30], for given wave natural (angular) frequency and body geometry. $f_{p}$ is expressed as:

$f_{p}=-C \dot{Z}-K Z$

Where $C$ and $K$ are PTO damping (that is, when acting as a generator) and PTO spring (when acting as a motor), respectively. Since it is desired that the PTO act as generator only, the spring constant in equation7 is ignored. Therefore, equation 3.3 was re-written as:

$(M+A) \ddot{Z}+(B+C) \dot{Z}+(\rho g S) Z=f_{e}$

For regular waves of (angular) frequency $\omega_{\mathrm{w}}$, the excitation force $\left(f_{e}\right)$ is a simple harmonic function of time $(\mathrm{t})$, expressed as: 
$f_{e}=F_{e} \operatorname{Cos}\left(\omega_{w} t\right)$

Where $\mathrm{F}_{\mathrm{e}}$ is the amplitude of the excitation force $(\mathrm{N})$ and $\omega_{\mathrm{w}}$ is the regular wave frequency $(\mathrm{Hz})$.

The general solution of equation (8) is obtained by adding a particular solution of equation (9) to the complementary solution of the homogeneous equation (i.e. $f_{e}=0$ in equation 8). The complementary function represents a transient motion, which is eventually damped out; while the particular solution leads to steady state, which is the focus of this model. The amplitude of the excitation force is obtained as [31]-[32],

$F_{e}=\sqrt{\frac{2 . \rho \cdot B \cdot g^{3}}{\omega_{w}^{3}}} \cdot A_{w}$

Where, $A_{w}$ is the incident wave amplitude (m). Hnce, equation 8 takes the form of;

$$
\begin{aligned}
& (M+A) \ddot{Z}+(B+C) \dot{Z}+(\rho g S) Z= \\
& \sqrt{\frac{2 \cdot \rho \cdot B \cdot g^{3}}{\omega_{w}^{3}}} \cdot A_{w} \operatorname{Cos}\left(\omega_{w} t\right)
\end{aligned}
$$

According to [31], the optimal conditions for extracting the maximum wave energy are:

i) The natural oscillation frequency of the oscillating system must equal the wave frequency, that is, a condition of resonance must exist. That is:

$\omega_{\mathrm{sys}}=\omega_{\mathrm{w}}$ ii) The damping force coefficient for the PTO must equal the radiation damping coefficient. That is:

$$
B=C
$$

The hydrodynamic coefficients (added mass and radiation damping) were computed using strip theory. Based on the theory, the buoy was split into a number of transverse panels or strips. Each strip was treated as a two dimensional section in order to compute its hydrodynamic characteristics. Each strip individual coefficient was then integrated along the entire length of the buoy to obtain the buoy's overall coefficients.

\section{Simulation of the concept device}

Simulation of the WEC system in the time domain was executed using the Matrix Laboratory (MATLAB R2009a). The simulations were used to obtain the buoy's displacement, velocity, and acceleration, while the power extracted by the PTO was obtained using:

$P=C(\dot{Z})^{2}$

Duration of each simulation was sixty seconds and waves with different amplitudes and periods typical of the Gulf of Guinea coast of Nigeria are employed (as derived from www.buoyweather.com. The impute parameters, constituting the sea states, are described by both the significant wave height $\mathrm{H}_{\mathrm{s}}$ and the corresponding energy period $\mathrm{T}_{\mathrm{e}}$. Shown in Table 1 are the sea states used as imputes in the simulations.

TABLE 1.

SEA STATES PARAMETERS USED FOR THE SIMULATION

\begin{tabular}{rcc}
\hline Sea state & $\mathbf{H}_{\mathbf{s}}(\mathbf{m})$ & $\mathbf{T}_{\mathbf{e}}(\mathbf{s})$ \\
\hline $\mathbf{1}$ & 0.4 & 08 \\
$\mathbf{2}$ & 0.8 & 10 \\
$\mathbf{3}$ & 1.2 & 12 \\
$\mathbf{4}$ & 1.5 & 14 \\
$\mathbf{5}$ & 2.0 & 16 \\
\hline
\end{tabular}

$\mathrm{H}_{\mathrm{s}}=$ Significant wave height; $\mathrm{T}_{\mathrm{e}}=$ Energy period.

The output parameters obtained from the simulations were buoy's displacements, velocity, acceleration and force, as well as the WEC's instantaneous power output. In order to evaluate the device performance, the Capture Width Ratio (CWR) was calculated for each simulated sea state. This measure of performance is a frequently used performance index of WEC technologies [33].The CWR was computed as,

$\mathrm{CWR}=\frac{P_{a b s}}{\mathrm{~J} \cdot \mathrm{D}}$

Where $\mathrm{P}_{\text {abs }}$ is mean absorbed power, $\mathrm{D}$ is device buoy horizontal extent $(\mathrm{m})$ and $\mathrm{J}$ is the wave power per unit of wave front length, as given in Equation 1.

\section{RESULT AND DISCUSSION}

Motion response (displacement, velocity and acceleration) of the concave wedge buoy is as shown in Figures $4 \mathrm{a}$ to $4 \mathrm{e}$. The steady state maximum instantaneous velocity increases from $0.2 \mathrm{~m} / \mathrm{s}$ for sea state 1 up to $0.47 \mathrm{~m} / \mathrm{s}$ for sea state 5 , and for a fixed value of external damping (PTO), the increase in velocity implies greater power output (Equation 13). The maximum instantaneous acceleration values also increases from $0.17 \mathrm{~m} / \mathrm{s}^{2}$ for sea state 1 to $0.19 \mathrm{~m} / \mathrm{s}^{2}$ for sea state 5.The figures show that the buoy achieves steady state motion (displacement) from 2.8 seconds for sea state 1 up to 4.7 seconds for sea state 5 . 
Figures $5 \mathrm{a}$ to $5 \mathrm{e}$ present the behaviour of the conecylinder buoy, which has motion response pattern that is similar to that of concave wedge buoy, except that there is a general reduction in the output parameters' magnitude. The figures show that the buoy achieves steady state motion (displacement) from 2.4 seconds for sea state 1 up to 4.5 seconds for sea state 5; steady state maximum instantaneous velocity increases from $0.15 \mathrm{~m} / \mathrm{s}$ for sea state 1 up to $0.32 \mathrm{~m} / \mathrm{s}$ for sea state 5 ; and maximum instantaneous acceleration values also increases in values from $0.11 \mathrm{~m} / \mathrm{s}^{2}$ for sea state 1 to $0.13 \mathrm{~m} / \mathrm{s}^{2}$ for sea state 5 . The initial spike in values, observed especially in velocity and acceleration before steady state was achieved, is due to the effect of the complimentary function or general solution of

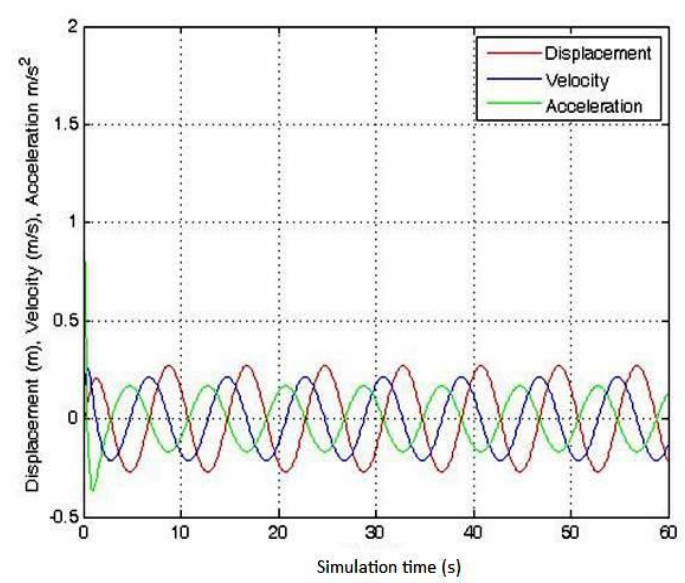

(a)

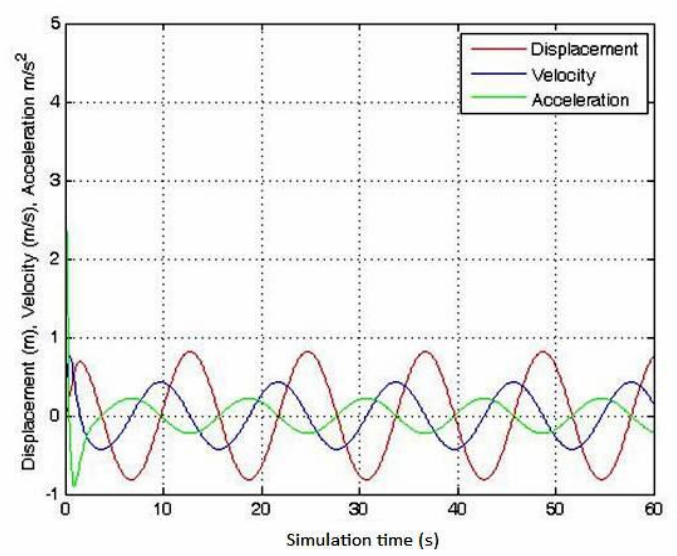

(c)
Equation 8 when set to zero (that is, no external forcing function). This represents a transient motion which is eventually damped out.

The output parameters, when compared for the buoys, shows that for each sea state simulated, the concave wedge buoy consistently gave greater output values for each of displacement, velocity, and acceleration than cone-cylinder buoy. These have implications for power production. Power production depends on the PTO damping factor as well as the buoy velocity (Equation 13), showing that the concave wedge buoy will output relatively greater power than the cone-cylinder buoy.

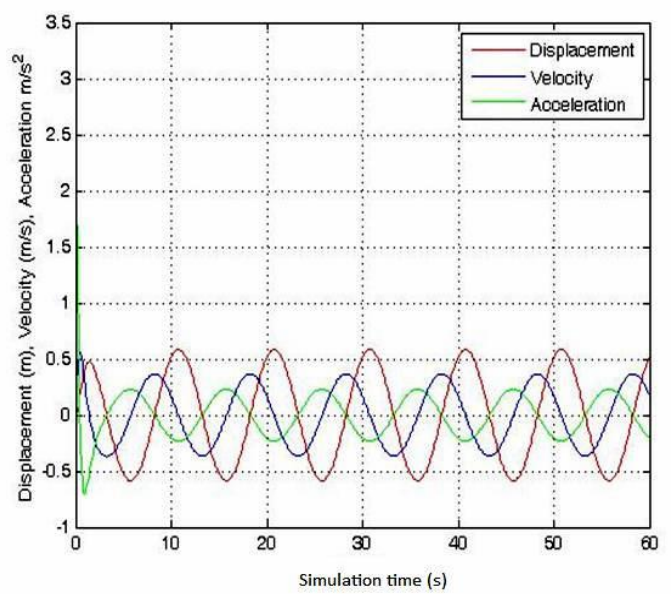

(b)

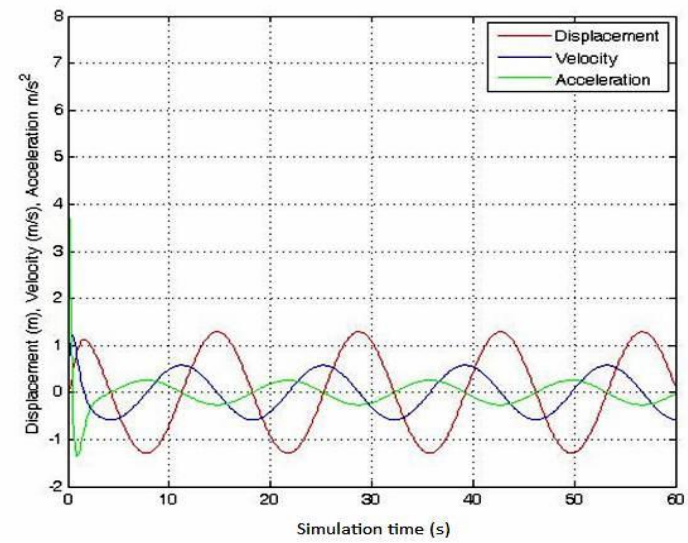

(d)

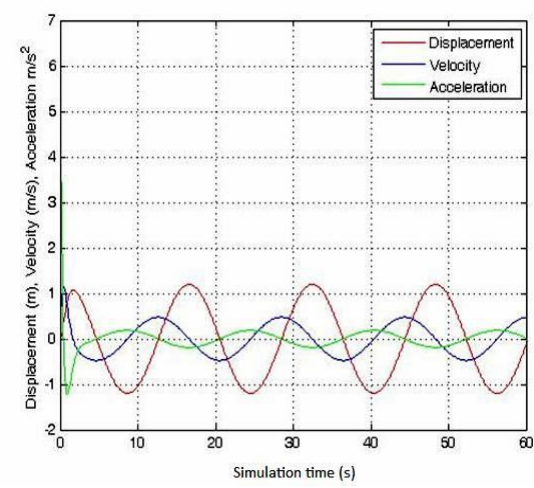

(e)

Figure. 4. (a) Concave wedge buoy motion response for sea state $1(\mathrm{Hs}=0.4 \mathrm{~m}, \mathrm{Te}=8 \mathrm{~s})$, (b) Concave wedge buoy motion response for sea state $2(\mathrm{Hs}=0.8 \mathrm{~m}, \mathrm{Te}=10 \mathrm{~s})$, (c) Concave wedge buoy motion response for sea state $3(\mathrm{Hs}=1.2 \mathrm{~m}, \mathrm{Te}=12 \mathrm{~s})$, (d) Concave 
International Journal of Marine Engineering Innovation and Research, Vol. 4(3), Sept. 2019. 164-173 (pISSN: 2541-5972, eISSN: 2548-1479)

wedge buoy motion response for sea state $4(\mathrm{Hs}=1.5 \mathrm{~m}, \mathrm{Te}=14 \mathrm{~s})$, (e) Concave wedge buoy motion response for sea state $5(\mathrm{Hs}=$ $2.0 \mathrm{~m}, \mathrm{Te}=16 \mathrm{~s})$.

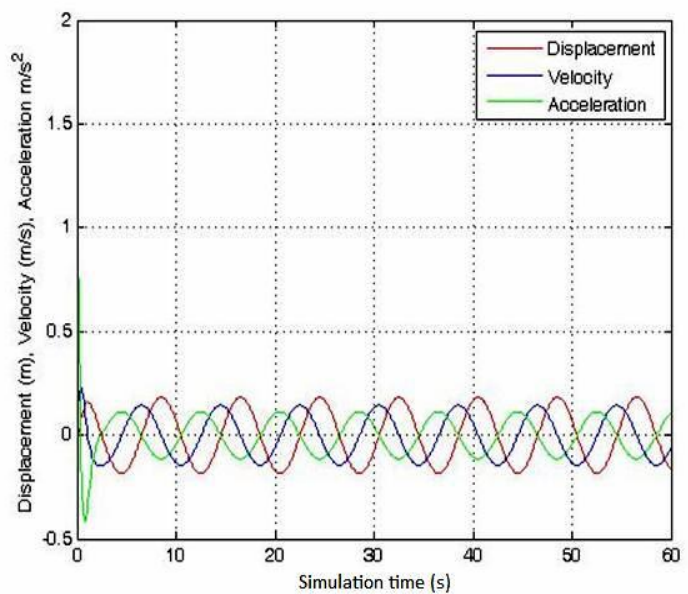

(a)

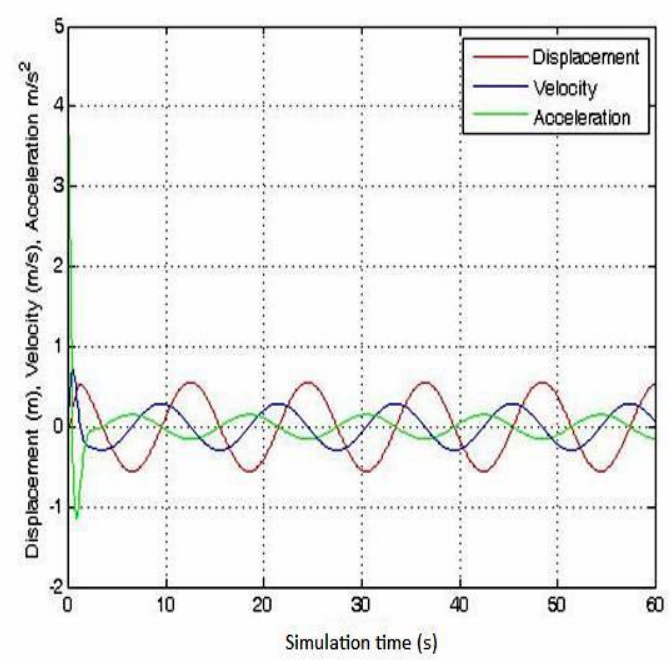

(c)

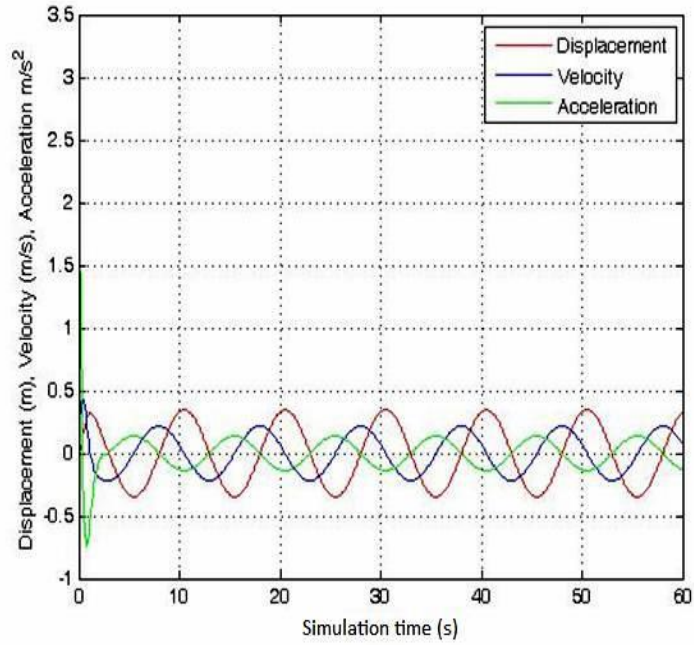

(b)

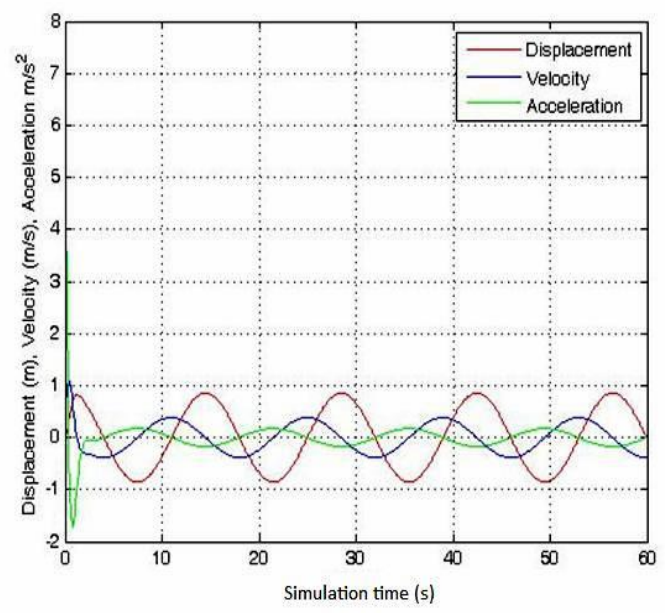

(d)

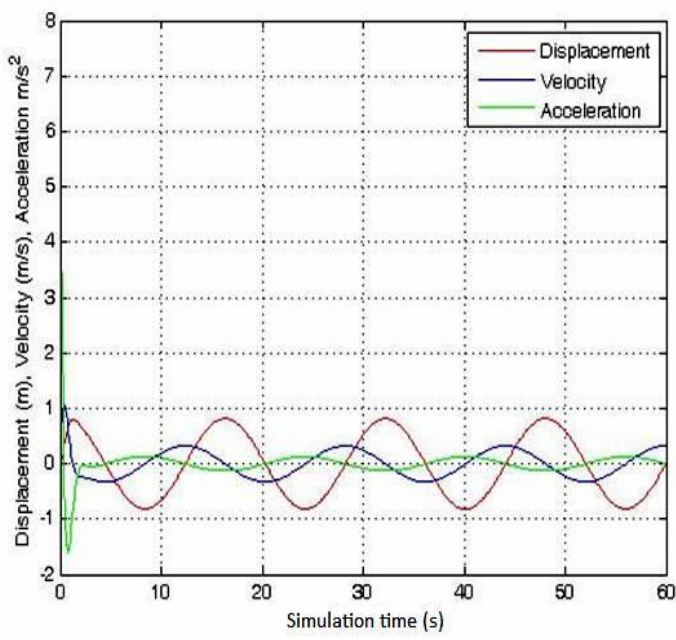

(e)

Figure. 5. (a) Cone-cylinder buoy motion response for sea state $1(\mathrm{Hs}=0.4 \mathrm{~m}, \mathrm{Te}=8 \mathrm{~s}$ ), (b) Cone-cylinder buoy motion response for sea state 2 (Hs= $0.8 \mathrm{~m}, \mathrm{Te}=10 \mathrm{~s})$, (c) Cone-cylinder buoy motion response for sea state $3(\mathrm{Hs}=1.2 \mathrm{~m}, \mathrm{Te}=12 \mathrm{~s})$, (d) Cone-cylinder buoy motion response for sea state $4(\mathrm{Hs}=1.5 \mathrm{~m}, \mathrm{Te}=14 \mathrm{~s})$, (e) Cone-cylinder buoy motion response for sea state $5(\mathrm{Hs}=2.0 \mathrm{~m}, \mathrm{Te}=16 \mathrm{~s})$,

Instantaneous power output of the Concave Wedge buoy is as presented in Figures 6a through 6e, while that of Cone-cylinder buoy is as shown in Figures 7a through 7e. As observed in motion response, the pick instantaneous power for steady state conditions for the buoys increases with the magnitude of the sea states. For the concave wedge it increases from 2.04 $\mathrm{kW}$ for sea state 1 to $10.14 \mathrm{~kW}$ for sea state 5 , while for 
the Cone-cylinder buoy it varies from $0.94 \mathrm{~kW}$ for sea state 1 to $4.7 \mathrm{~kW}$ for sea state 5 .The mean power output for the Concave wedge buoy range from 1.04 $\mathrm{kW}$ for sea state 1 to $5.56 \mathrm{~kW}$ for sea state 5 , with corresponding standard deviations of $0.733 \mathrm{~kW}$ and $5.96 \mathrm{~kW}$ respectively. In the case of the Cone-cylinder buoy, the mean power output range from $0.49 \mathrm{~kW}$ for sea state 1 to $2.85 \mathrm{~kW}$ for sea state 5 , with corresponding standard deviations of $0.368 \mathrm{~kW}$ and $4.54 \mathrm{~kW}$ respectively. The initial high spike in the instantaneous power output for each simulation is due to the effect of transient motion effect on buoy velocity which is eventually damped out as the motion

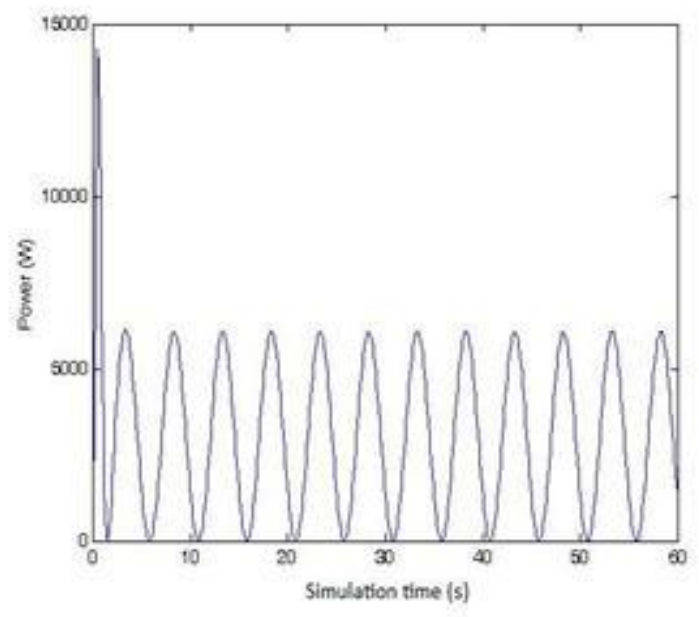

(a)

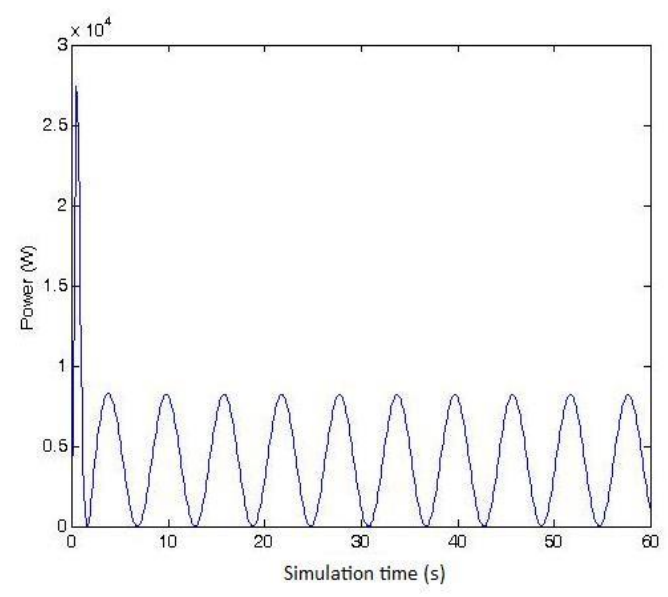

(c)

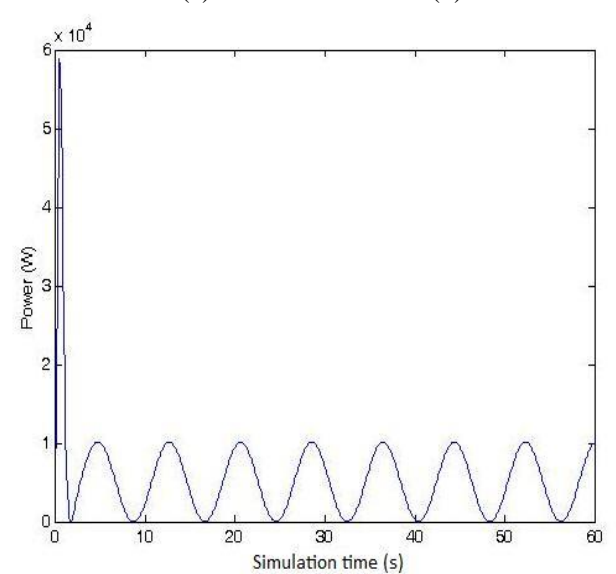

(e) response achieves steady state. The plot of mean output power as against the sea states for the two types of buoys considered is as shown in Fig. 8, while Fig. 9 shows the capture width ratio for the two buoys across the selected sea states. A look at the Fig. 8 shows that the optimum sea state for the two buoys peaked at sea state 4 , with concave wedge buoy having an optimal power output of $8 \mathrm{~kW}$ and cone-cylinder optimal power output being $3.7 \mathrm{~kW}$. Also deduced from the graphs is that the wedge buoy consistently gives relatively greater power output than the cone cylinder buoy.

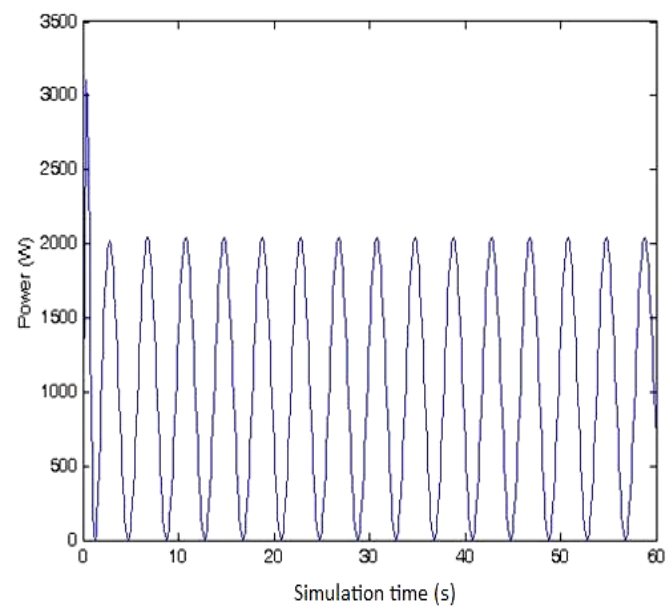

(b)

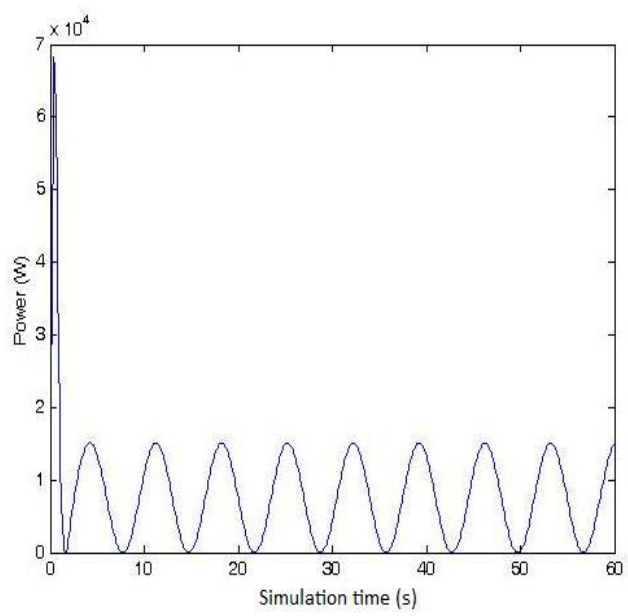

(d) 
Figure. 6. (a) Concave-wedge buoy instantaneous power output for sea state $1(\mathrm{Hs}=0.4 \mathrm{~m}, \mathrm{Te}=8 \mathrm{~s})$, (b) Concave-wedge buoy instantaneous power output for sea state $2(\mathrm{Hs}=0.8 \mathrm{~m}, \mathrm{Te}=10 \mathrm{~s})$, (c) Concave-wedge buoy instantaneous power output for sea state $3(\mathrm{Hs}=1.2 \mathrm{~m}, \mathrm{Te}=12 \mathrm{~s}$ ), (d) Concavewedge buoy instantaneous power output for sea state $4(\mathrm{Hs}=1.5 \mathrm{~m}, \mathrm{Te}=14 \mathrm{~s})$, (e) Concave-wedge buoy instantaneous power output for sea state 5 $(\mathrm{Hs}=2.0 \mathrm{~m}, \mathrm{Te}=16 \mathrm{~s})$

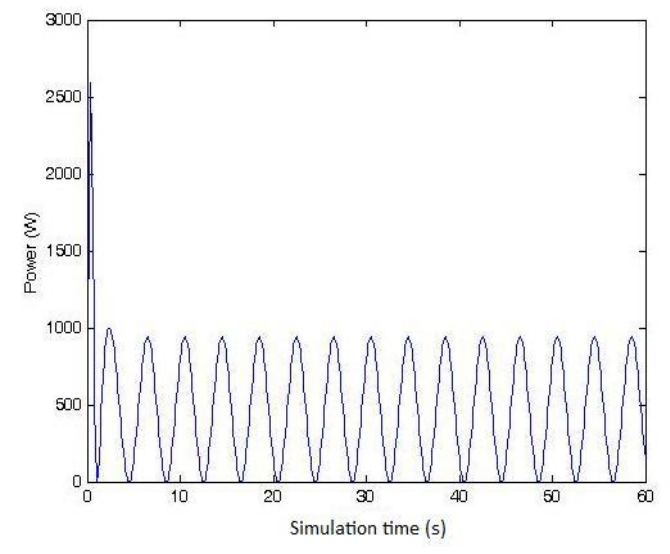

(a)

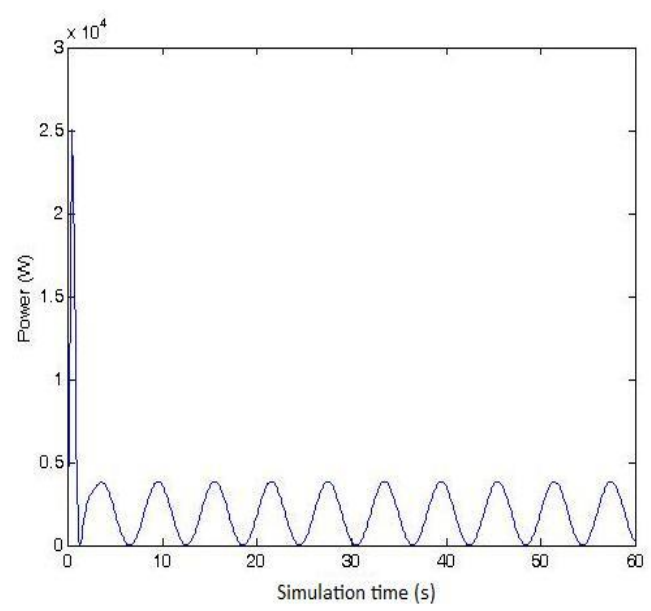

(c)

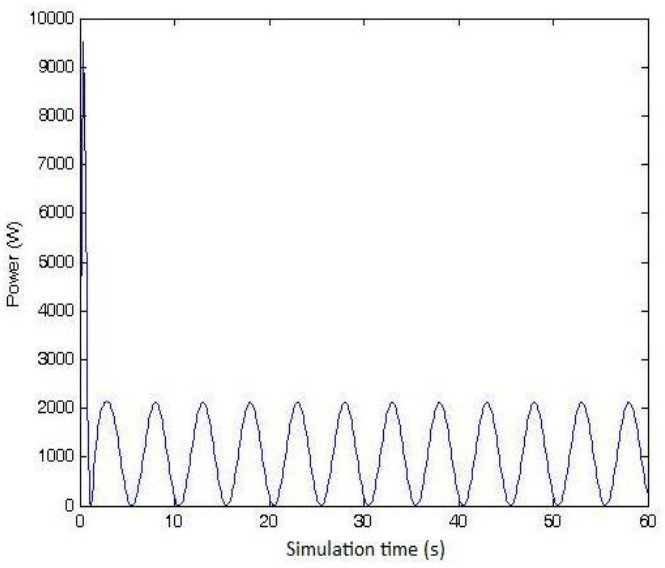

(b)

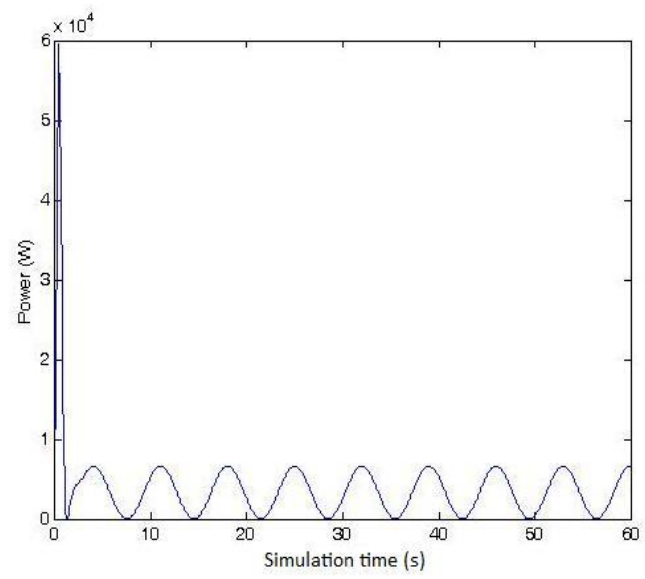

(d)

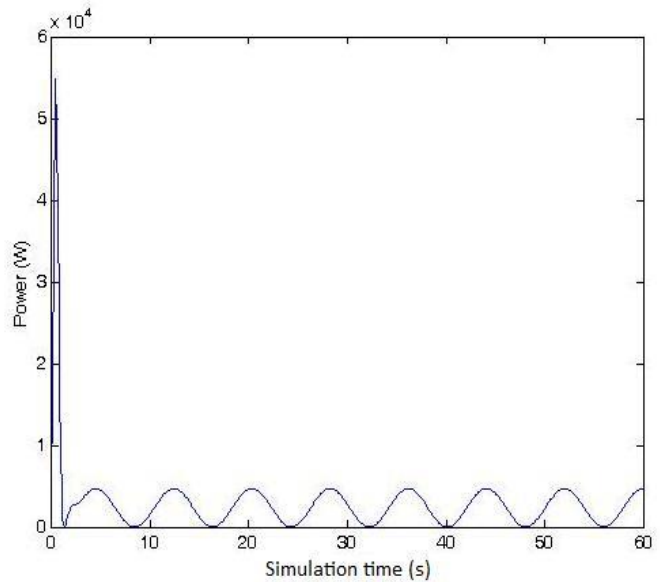

(e)

Figure. 7. (a) Cone-cylinder buoy instantaneous power output for sea state $1(\mathrm{Hs}=0.4 \mathrm{~m}, \mathrm{Te}=8 \mathrm{~s})$, (b) Cone-cylinder buoy instantaneous power output for sea state $2(\mathrm{Hs}=0.8 \mathrm{~m}, \mathrm{Te}=10 \mathrm{~s})$, (c) Cone-cylinder buoy instantaneous power output for sea state $3(\mathrm{Hs}=0.2 \mathrm{~m}, \mathrm{Te}=12 \mathrm{~s})$, (d) Conecylinder buoy instantaneous power output for sea state $4(\mathrm{Hs}=1.5 \mathrm{~m}, \mathrm{Te}=14 \mathrm{~s})$, (e) Cone-cylinder buoy instantaneous power output for sea state $5(\mathrm{Hs}=2.0 \mathrm{~m}, \mathrm{Te}=16 \mathrm{~s})$ 


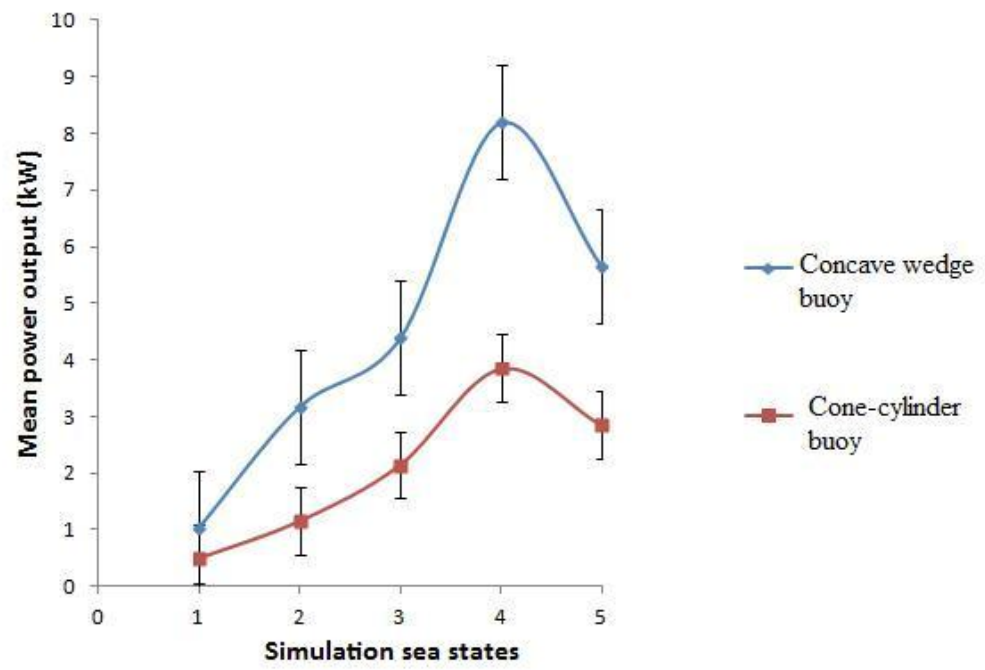

Figure. 8. Mean power output versus Sea state for the concave wedge buoy and cone-cylinder bouy

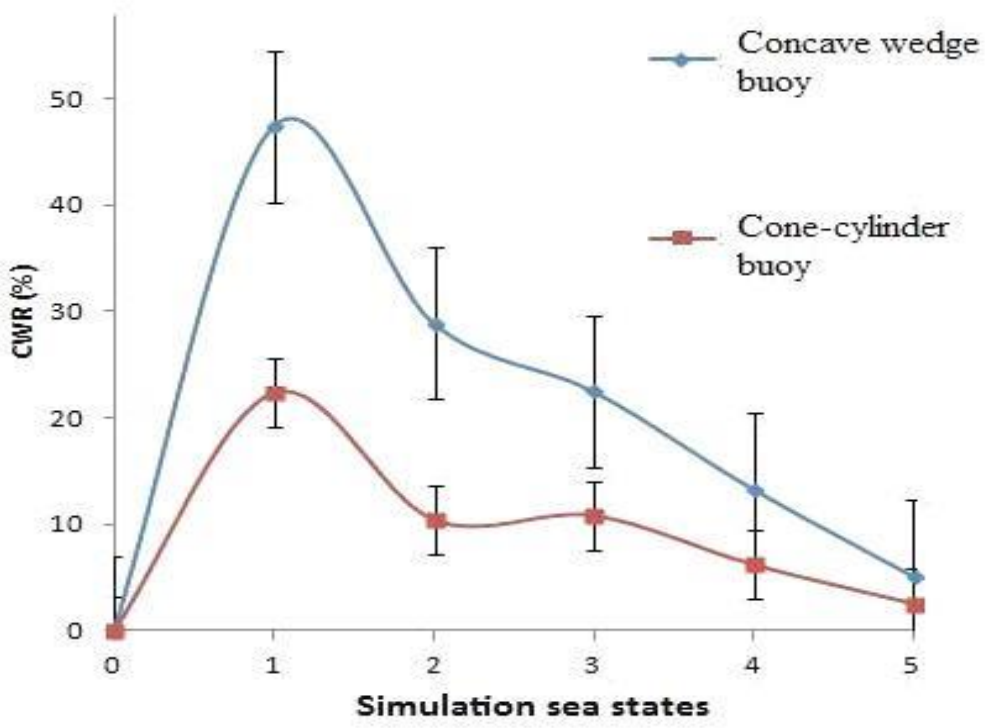

Figure. 9. Capture width ratio of the two buoys investigated as a function of simulation sea states.

\section{IV.CONCLUSION}

For the five sea state levels considered, the mean power output for the two buoy is lowest at sea state $1\left(\mathrm{H}_{\mathrm{s}}=0.4\right.$ $\left.\mathrm{m}, \mathrm{T}_{\mathrm{e}}=8 \mathrm{~s}\right)$ at $1.04 \mathrm{~kW}$ and $0.49 \mathrm{~kW}$ for Concave wedge shaped buoy and cone-cylinder composite buoy respectively. However, the optimum sea state for the two buoys peaked at sea state $4\left(\mathrm{H}_{\mathrm{s}}=1.5 \mathrm{~m}, \mathrm{~T}_{\mathrm{e}}=14 \mathrm{~s}\right)$, with concave wedge buoy having an optimal power output of $8 \mathrm{~kW}$ and cone-cylinder optimal power output being $3.7 \mathrm{~kW}$. Also deduced from the graphs is that the wedge buoy consistently gives relatively greater power output than the cone cylinder buoy. The concave wedge buoy is thus the one with optimum power output among the two shapes considered as being appropriate for the concept point absorber WEC. Though the optimal power output is modest, this may be improved upon by mounting several similar buoys in the throat section, and the amplification of the incident wave energy content by the WAD will significantly increase energy output per buoy, bearing in mind that the wave parameters as presented by nature was used for the simulation.

\section{REFERENCES}

[1] Bosma, B. 'On the Design, Modelling, and Testing of Ocean Wave Energy Converters. Ph.D. dissertation submitted to School of Electrical Engineering and Computer Science, Oregon State University, Corvallis, Oregon, USA; 2013.

[2] Gunn, K., and Stock-Williams, C. 'Quantifying the Global Wave Power Resources'. Renewable Energy. 2012; 1-9.

[3] Pontes, M., and Falcao, A. 'Ocean energies: Resources and utilisation. In Proceedings of the $18^{\text {th }}$ Congress of the World Energy Council, Buenos Aires, Argentina. 2001.

[4] Emmanuel, A. A and Akinbode, T. (2012) 'Communal Facilities in Coastal Settlements of Ondo State, Nigeria: Assessment of Community-Based Organisations' Efforts Using the Facility Contributory Index Model' British Journal of Education, Society \& Behavioural Science 2(2): 150 - 161.

[5] Olufayo, O., Omole, F., and Lawanson, T. (2013). 'Utilizing Creeks for Integrated Rural Coastal Development of Ilaje Area of Nigeria'. Ethiopian Journal of Environmental Studies and Management 6(3), 294-299

[6] UNEP. Ocean Energy Potential of the West African Region. UNEP Regional Seas Reports and Studies. 1983; no.30. 
[7] Falcao, A.F. 'Wave energy utilization: a review of the technologies' Renewable Sustainable Energy Rev. (2010) 14(3): 899-918.

[8] Akpınar, A. and Kömürcü, M. I. 'Wave energy potential along the south-east coasts of the Black Sea'. Energy 42 (2012) 289 302 .

[9] Beirao, P. and Malca, C. (2014) 'Design and analysis of buoy geometry for a wave energy converter' International Journal of Energy and Environmental engineering (Springer) 5: 91-96

[10] Pastor, J., and Liu, Y.-C.: 'Hydrokinetic energy overview and energy potential for the Gulf of Mexico'. In: IEEE Green Technologies Conference, Tulsa, OK 2012

[11] Kim, J. Koh, H.J. Cho, I.H. Kim, M.H., and Kweon, H.M. 'Experimental study of wave energy extraction by a dual-buoy heaving system'. International Journal of Naval Architecture and Ocean Engineering 9 (2017) 25-3-4.

[12] Goggins, J. and Finnegan, W. 'Shape Optimisation of Floating Wave Energy Converters for a Specified Wave Energy Spectrum'. Renewable Energy 71 (2014) 208- 220

[13] Marqués, J., and Torre-Enciso, Y. The Basque Country: A Strategic Commitment to Leading the Wave Energy Sector. 3rd International Conference on Ocean Energy, 6 October, Bilbao, 4 pages.

[14] Michailides, C. and Angelides, C. "Modeling of energy extraction and behavior of a Flexible Floating Breakwater," Applied Ocean Research, vol. 35, pp. 77-94, 2012.

[15] He, F., and Huang, Z. "Hydrodynamic performance of pilesupported OWC-type structures as breakwaters: An experimental study," Ocean Engineering, vol. 88, (2014). 618-626

[16] Ning, D., Zhao, X., Goteman, M., and Kang,H. "Hydrodynamic performance of a pile-restrained WEC-type floating breakwater: An experimental study," Renewable Energy, vol. 95, (2016) 531541 ,

[17] Zheng, S., and Zhang, Y. "Wave diffraction and radiation by multiple rectangular floaters," Journal of Hydraulic Research, vol. 54, no. 1, (2016) 102-115,

[18] Zhao, X., Ning. D., Zhang, C., Liu, Y., and Kang, H. 'Analytical Study on an Oscillating Buoy Wave Energy Converter Integrated into a Fixed Box-Type Breakwater'. Mathematical Problems in Engineering Volume 2017, Article ID 3960401, 9 pages. https://doi.org/10.1155/2017/ 3960401

[19] Brooks, J. Elsevier Ocean Engineering Book Series; Wave Energy Conversion. Elsevier, Amsterdam; 2003.

[20] Madhi, F., Sinclair, M. E., and Yeung, R. W. The Berkeley Wedge: an Asymmetrical Energy-capturing Floating Breakwater of High Performance. Marine Systems \& Ocean Technology. (2014); 9 (1): 5-16.

[21] Hardisty, J. Experiments with Point Absorbers for Wave Energy Conversion. Journal of Marine Engineering and Technology. (2012); 11(1): 51-62.

[22] Sarlak, H., Seif, M. S., and Abbaspour, M. Experimental Investigation of Offshore Wave Buoy Performance. Journal of Marine Engineering. (2010); 6(11), 1-11.

[23] Aderinto, T. and Li, H. Ocean Wave Energy Converters: Status and Challenges. Energies. (2018); 11, 1250; 1-26.

[24] De Backer, G. Hydrodynamic Design Optimization of Wave Energy Converters Consisting of Heaving Point Absorbers. PhD thesis, Faculty of Engineering, Ghent University, Netherlands; 2009 .

[25] Wacher, A. and Nielsen, K. Mathematical and Numerical Modelling of The Aqua BuOY Wave Energy Converter. Mathematics-In-Industry Case Studies. (2010); 2: 16-33.

[26] Engstrom, J. Hydrodynamic Modelling for a Point Absorbing Wave Energy Converter. Ph.D. dissertation, Uppsala University, Sweden; 2011.

[27] Pastor, J. and Liu, Y. Frequency and Time Domain Modelling and Power Output for a Heaving Point Absorber Wave Energy Converter. International Journal of Energy, Environment and Engineering. (2014); 5:101.

[28] Kim, M. H., and Cho, H. I. A Novel Wave Energy Converter using Relative Motions between Buoy, Submerged Buoy, and Inner Dynamic System. Proceedings of the 1st Marine Energy Technology Symposium METS13.April 10-11, 2013, Washington, D.C.
[29] Lewis, T. M. A Remotely Operated, Autonomous Wave Energy Converter System. Ph.D. Dissertation Department of Electrical and Computer Engineering Oregon State University, Oregon, USA; 2014.

[30] Journee, J. M. J. Quick strip theory calculations in ship design. PRADS'92Conference on Practical Design of Ships and Mobile Structures, January, 1992, Newcastle upon Tyne, UK.

[31] Falnes, J. Ocean Waves and Oscillating Systems. Cambridge University Press, Cambridge, UK; 2002

[32] Falcao, A.F. Modelling and controlled of Oscillating body wave energy converters with hydraulic power take off and gas accumulator. Ocean engineering. (2007); 34, 2021- 2032.

[33] Hagerman, G., and Bedard, R. Guidelines for Preliminary Estimation of Power Production by Offshore Wave Energy Conversion Devices, EPRI; 2003

[34] Waters, R., Rahm, M., Svensson, O., Stromstedt, E., Bostrom, C., Sundberg, J., and Leijon, M. Ocean wave energy absorption in response to wave period and amplitude- offshore experiments on a wave energy converter. IET Renewable Power Generation. (2011)5: 465-469. 